\title{
Reorganization of The Journal of the Magnetics Society of Japan
}

It is my great pleasure to announce the reorganization of the Journal of the Magnetics Society of Japan to have the English title as the official journal title effective from the current issue. The front cover design is also renewed hoping the brilliant future of magnetics. We will use the Japanese Journal title of “Nihon Jiki Gakkai-Shi (日本磁気学会誌)" only for convenience hereafter. This is the first big change in the history of The Magnetics Society of Japan since 1977 and it symbolizes our direction to contribute more to the international magnetics community by sending sophisticated knowledge and information from far-east Asia using the world's popular language of English.

Such reorganization corresponds to the fresh restart of our society with the new Japanese society name of “Nihon Jiki Gakkai (日本磁気学会)” on October 1st, 2007. The English society name stays with "The Magnetics Society of Japan." The new Japanese name is so established to come back to our original standpoint to get together all who are interested in any area of magnetics including physics, chemistry, material science, technology and interdisciplinary technological applications. Actually special attention is paid to encourage physicists who had long been hesitated to join us because of our former name of "Nihon Oyo Jiki Gakkai (日本応用磁気学会),” which includes a word of “Oyo (応用, applications)" since the society establishment in 1977.

Our current understanding is that the single word "Jiki" counts on all the aspects of magnetics including both fundamental edge of physics and chemistry, and cutting edge of industrial applications, as was well described in the messages of the current and former presidents in the October 2007 issue of "Magnetics Japan (まぐね)” 1),2).

On the other hand, we are aware of certain anxiety of the society members that our society is loosing interests on traditional applied magnetics because of the removal of the word "Oyo" from the Japanese society name. -This will never happen. Remember the importance of world-wide energy and environmental problems. It is the high efficiency electromagnetic generator and transformer that bring valuable electric energy from any kind of power station to our home, office and industrial plant. It is the small, quiet and high efficiency motor and actuator that will bring the era of hybrid/electric motor vehicles. Soft/hard magnetic materials and applied magnetics technology are definitely the technology drivers in these areas. They should always stay with us as before.

Therefore the editorial committee plan to have more chance to include topics from physics and applied magnetics in the coming issues of "Magnetics Japan" to show the members how we really think these two areas are important. Of course, we will keep interest on hot topics from thin film, spin electronics, recording technologies, etc as well. The planning committee shares similar understanding; You may remember the special session on the state-of-the-art and future prospects of magnetics, held during the The 31st Annual Conference on MAGNETICS in Japan, September $12^{\text {th }}, 2007$, Gakushuin University. Three presentations out of six were devoted to applied magnetics technologies.

Back to the issues of reorganization of the journal, our first choice of language has been shifted to English. Nevertheless we will continue receiving Japanese papers as before because of the strong request from the members thinking of education for young students. Everyone knows it would be nice to publish first few papers in their mother tongue to focus on how to summarize technical papers without language issues.

In this sense, we are still on-going the midway. We would continue the discussion on how to balance the inter-nationality and intra-nationality aspects every few years.

The society board is only able to try to extend our activities from the intra-nation community to the inter-national community, which is likely to cause a new wind from Japan to Asia and worldwide. It is you who feel the wind, get the wind and accelerate the wind toward the future.

\section{Masahiro Yamaguchi \\ Editor-in-Chief \\ The Magnetics Society of Japan \\ Received: November $15^{\text {th }}, 2007$.}

\section{References}

1) T. Osaka, "Implication of Changing the Japanese Name of Our Society -Toward Reformation and Expansion of Our Development Activities-," Magnetics Japan, 2, 481 (2007).

2) H. Miyajima, "The Start of New MSJ towards the More Active Society," Magnetics Japan, 2, 482-486 (2007). 